\title{
Thermodynamic and kinetic study of the recovery of tungsten and cobalt from tool waste
}

\author{
Estudio termodinámico y cinético de la recuperación de wolframio y cobalto a partir de \\ residuos de herramientas
}

\author{
Sebastián Sierra-Pérez ${ }^{1}$, Néstor Ricardo Rojas-Reyes ${ }^{1 *}$, José Martínez-Zambrano², Hugo Alfonso Rojas-Sarmiento \\ ${ }^{1}$ Facultad de Minas, Departamento de Materiales y Minerales, Universidad Nacional de Colombia. Carrera 65 \# 63-20, Bloque 54. C.P. \\ 050034. Medellín, Colombia. \\ ${ }^{2}$ Facultad de Ciencias, Escuela de Ciencias Químicas, Universidad Pedagógica y Tecnológica de Colombia UPTC. Avenida Central del \\ Norte. C.P. 150003. Tunja, Colombia.
}

ARTICLE INFO:

Received: Abril 26, 2018

Accepted: Octubre 02, 2018

\section{AVAILABLE ONLINE:}

November 27, 2018

\section{KEYWORDS:}

Tungsten, Cobalt, OPT/RPT, thermodynamics, non-isothermic kinetics

Wolframio, Cobalto, OPT/RPT, termodinámica, cinética no isotérmica

\begin{abstract}
In the present research work, the recovery of tungsten and cobalt from waste coming from tungsten carbide-cobalt (WC-Col tools, which are widely used in the metalworking industry, was analyzed. The WC-Co waste was characterized by X-ray diffraction and scanning electron microscopy with microanalysis (SEM/EDS). The process started with the oxidation of the waste to obtain a mixture of oxides $\left(\mathrm{WO}_{3}\right.$ and $\left.\mathrm{CoWO}_{4}\right)$. The $\Delta \mathrm{H}$ and $\Delta \mathrm{G}$ were calculated both for the oxidation and reduction processes. Thermodynamic and non-isothermal kinetic analyses were carried out to obtain a stability diagram where theoretical and experimental data are defined by transformation lines as a function of temperature; in addition, the apparent activation energy was determined. By a hydrogen reduction process, high-purity tungsten and cobalt in metallic form were obtained.
\end{abstract}

RESUMEN: En el presente proyecto se analiza la recuperación de wolframio y cobalto a partir de residuos de herramientas fabricadas con carburo de wolframio - cobalto (WC-Co), las cuales son muy empleadas en la industria metalmecánica. El residuo de WC-Co se caracterizó por difracción de rayos $\mathrm{X}$ y microscopia electrónica de barrido con microanálisis (SEM/EDS). El proceso inició con la oxidación del residuo para obtener una mezcla de óxidos $\left(\mathrm{WO}_{3}\right.$ y $\left.\mathrm{CoWO} \mathrm{W}_{4}\right)$. Se calculó el $\Delta \mathrm{H}$ y el $\Delta \mathrm{G}$ tanto para el proceso de oxidación como para el proceso de reducción. Un análisis termodinámico y un análisis cinético no isotérmico entregó una figura donde se combinan datos teóricos y datos experimentales con transformaciones perfectamente delimitadas; además se calculó la energía de activación aparente de este proceso. El proceso de reducción con hidrógeno entregó wolframio y cobalto en forma metálica con alta pureza..

\section{Introduction}

Tungsten carbide-cobalt alloys have been used worldwide for a long time in the manufacture of tools for sectors such as the metalworking industry, mining industry, oil industry, radioactive and aerospace shielding because of their properties, such as high density, high resistance to wear, tenacity and mechanical resistance [1].

The world production of tungsten amounts to approximately 95,000 tons per year (year 2017) and its price may vary depending on the conditions in which it is required; on the other hand, the world production of

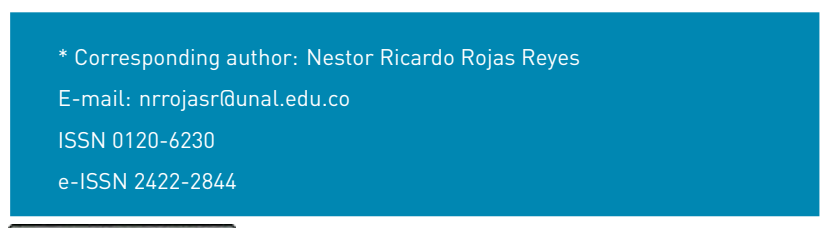

cobalt amounts to approximately 110,000 tons per year according to 2017 data [2]. The above data show that both tungsten and cobalt are considered as scarce materials and give an indication of the limitations of their deposits worldwide.

Tungsten carbide-cobalt tools are made of tungsten carbide agglomerated (or agglutinated) with cobalt, so that the content of cobalt can vary between $3 \%$ and $20 \%$ approximately [3]. Tungsten carbide has a melting point of $2870{ }^{\circ} \mathrm{C}$, whereas cobalt melts at $1495^{\circ} \mathrm{C}$ [4], so tools are usually made by sintering, since it requires a lower temperature to form the piece [5].

Currently, for the recycling of tungsten carbide-cobalt inserts various methods are used [6]. The simplest method of recovery is classified as direct and entails 
grinding the inserts until obtaining fines between 1 and 5 microns [5], which are then used to remanufacture inserts. This method is widely applied in Eastern countries, but only a small percentage of the global waste is processed in this way. In the United States about $60 \%$ of waste is processed by indirect methods [7], where $35 \%$ is recycled using chemical methods such as chlorination, oxidation and alkaline leaching, oxidation and reduction of oxides [1], and the other $25 \%$ is recycled by a method in which zinc is used in the liquid phase [8]. Of the remaining $40 \%$ of the waste generated in the United States, $5 \%$ is used in other processes and the final $35 \%$ is not recycled [7]. Furthermore, regardless of the method applied, it is common to see that around $20 \%$ of waste materials are recovered in the industry and are usually mixed with new raw materials for the manufacture of new products [8].

In 1985 Paul [9] described the different existing processes for the recycling of metals such as tungsten, titanium, tantalum and cobalt from cemented carbides. In 1989 Latha [10] developed a method similar to that described by Paul in 1985 for recycling tungsten, in which nitric acid is used as an electrolyte. This makes the method more efficient, due to a decrease in processing costs. In 2013, Altuncu [8] reported a process to remove the cobalt used as a binder in the tools made with tungsten carbide-cobalt, in which a zinc bath is used to immerse the tungsten carbide-cobalt tools. In 2012, Vesel [11] evaluated the phase transformations that occur in parts manufactured with tungsten carbide-cobalt when subjected to thermal treatment at different temperatures using plasma and concentrated radiation. In 2014, Kim [1] studied the behavior of cobalt dissolution in tungsten carbide-cobalt waste. The method consisted of the oxidative roasting of the wastes from which WO[3] tungsten oxides and cobalt-tungsten oxide CoWO[4] are obtained. The oxides are dissolved in a solution of sulfuric acid and hydrogen peroxide inside a ball mill, from which tungstic acid and a cobalt ion solution are obtained.

Based on the literature review, it is observed that the methods for obtaining compounds with a high content of tungsten and/or cobalt as a final product must be refined to finally obtain the material of interest; generally, hydrometallurgy, electrometallurgy and pyrometallurgy classics treatmets are not applied for the recycling of hard metals.

It is worth pointing out that due to the complexity involved in the recycling of this material, the developments reached so far leave paths to be explored in order to tackle issues related to both sustainability and the environment [8].

\section{Methodology}

After the characterization of the tungsten carbide-cobalt waste by XRD and SEM/EDX, the material was roasted at $900{ }^{\circ} \mathrm{C}$ for $3 \mathrm{~h}$ in a Terrígeno Industry 2600W furnace model D8 to obtain tungsten and cobalt oxides, which were then reduced in a hydrogen atmosphere to obtain tungsten and cobalt in metallic form. The experimental development of the present project was based on the following methodology:

- Characterization of the samples by X-ray diffraction (XRD) and scanning electron microscopy with microanalysis (SEM/EDS). The phases in both the starting material and the products obtained were identified by XRD using a PANalytical X'pert PRO MPD in a $2 \theta$ interval with a step of $0.02^{\circ}$ and an accumulation time of $56 \mathrm{~s}$, with a copper anode. For this analysis, the WC-Co base material, as well as the intermediate products $\left(\mathrm{CoWO}_{4}\right.$ and $\left.\mathrm{WO}_{3}\right)$ and the final products were ground to a particle size smaller than 75 microns. As a final step, the resulting diffraction pattern was analyzed using HighScore Plus software for phase identification. For the chemical composition of the WC-Co base material and the products obtained, scanning electron microscopy with semiquantitative backscattered electron analysis (SEM/EDS) was perfomed using PHENOM XL equipment with image analysis software as well.

- Calculation of thermodynamic parameters of the WC-Co system and the $\mathrm{WO}_{3}+\mathrm{CoWO}_{4}$ system. For the thermodynamic study of the oxidation and reduction processes, the HSC Chemistry 6.0 software for Microsoft Windows and its modules, equilibrium composition and reaction equations, were used.

- Analysis of results from OPT tests loxidation at programmed temperaturel applied to the WC-Co system and RPT (reduction at programmed temperaturel applied to the $\mathrm{WO}_{3}+\mathrm{CoWO}_{4}$ system. The kinetic study of the processing of both the base material and the products obtained was carried out in a MICROMERITICS AutoChem II Chemisorption Analyzer with data adquisition AutoChem II 2920 software 4.01 version. The apparent activation energy was calculated by Coats and Redfern method [12, 13].

- The products generated in the selected metallurgical process were characterized by XRD using a PANalytical X'pert PRO MPD under the same conditions as above. 


\section{Results and discussion}

\subsection{Identification of the material}

Tungsten carbide-cobalt (WC-Co) is a hard material that can easily be found in the metalworking industry, with different shapes depending on its use, with or without coatings depending on the working conditions. The coating may be titanium nitride (TiN) and alumina $\left(\mathrm{Al}_{2} \mathrm{O}_{3}\right)$. The coatings represent an additional barrier to the phase transformations required in the processing of the WC-Co system. The uncoated waste was selected as the experimental base material (see Figure 1), because the coating restricts the access of the oxidizing reagents inside the material. The waste used for this work was 6 , 12 and $16 \mathrm{~mm}$ in size, as is shown in Figure 2.

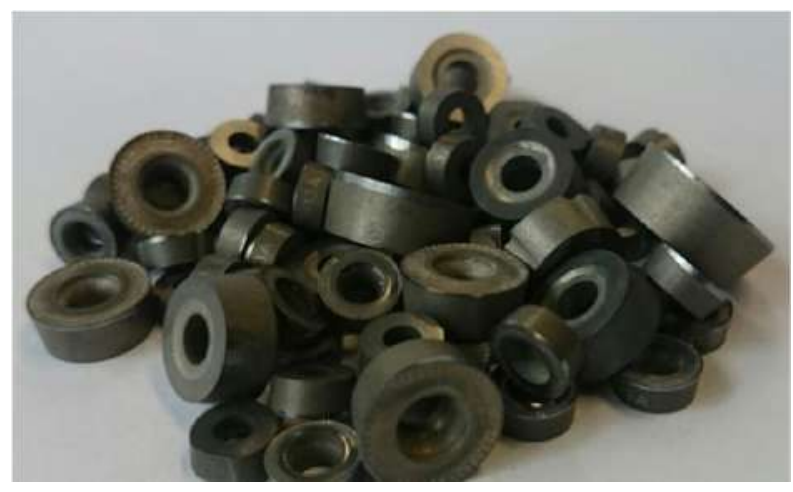

Figure 1 Waste of uncoated WC-Co

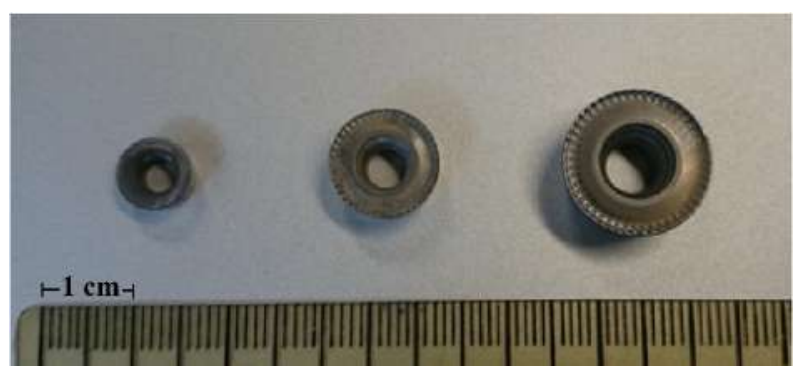

Figure 2 Relative size of WC-Co waste used in the project

\subsection{Characterization of the waste before and after roasting}

In order to characterize the starting material (WC-Co) by $X$-ray diffraction, a reduction of the particle size equal to 200 mesh was required. The XRD pattern of the WC-Co material powder (see Figure 3) shows that the tungsten carbide species of the study material correspond to the $\delta$-WC phase with structure and chrystallographic
Table 1 Elemental analysis of WC-Co waste by EDS

\begin{tabular}{cccc}
\hline $\begin{array}{c}\text { Element } \\
\text { name }\end{array}$ & $\begin{array}{c}\text { Element } \\
\text { symbol }\end{array}$ & $\begin{array}{c}\text { Element } \\
\text { number }\end{array}$ & $\begin{array}{c}\text { Element } \\
\text { weight }\end{array}$ \\
\hline Tungsten & W & 74 & 96.41 \\
Cobalt & Co & 27 & 0.61 \\
Carbon & C & 6 & 2.99 \\
\hline
\end{tabular}

parameters equal to those of the pattern obtained by Kurlov in 2006 [14]. In Figure 3, the presence of additional peaks corresponds to the cobalt contained in the study material. The analysis of the diffraction pattern was with HighScore Plus software, by means of a semiquantitative analysis, revealing that the sample contains $93 \%$ tungsten carbide and $7 \%$ cobalt, approximately.

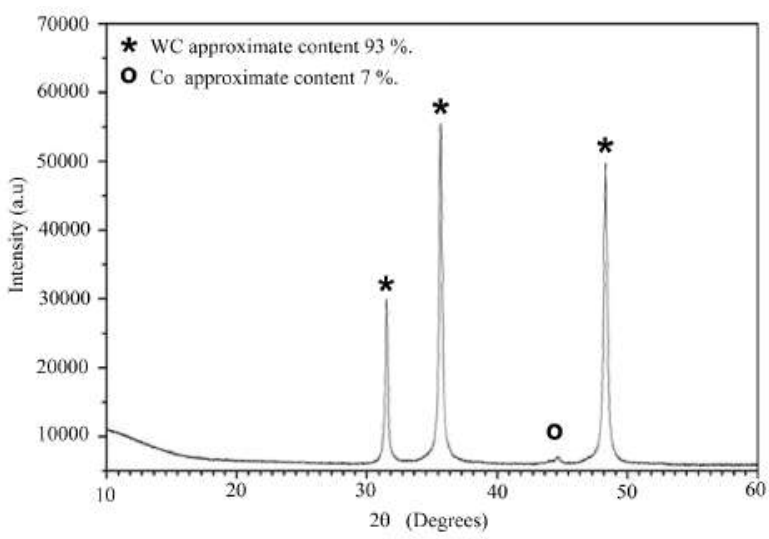

Figure 3 Diffraction pattern of WC-Co material

The elemental analysis by EDS showed that the study material is composed of carbon, cobalt and tungsten as main elements, with the percentages listed in Table 1. Figure 4 shows SEM/EDS images where the distribution of the elements can be seen, which are identified by colors that highlight the areas of each element; the predominant element is tungsten. The particle size of the powers was determined to be between 1 and 5 micrometers.

After the roasting process of the waste, the resulting material composed of tungsten and cobalt oxides was analyzed. Although some carbon appears in Table 2, this content is associated with the microscope sample conveyor belt, since carbide carbon is gasified in the form to carbon dioxide $\left(\mathrm{CO}_{2}\right)$.

Figure 5 shows an EDS mapping of the calcined sample. The oxide particles are below 1 micrometer in size with heterogeneous shapes and no sharp angles. This analysis of the phases using EDS mapping confirmed that the majority are oxides, namely, tungsten oxide, cobalt oxide and complex tungsten-cobalt oxides, distributed in a 


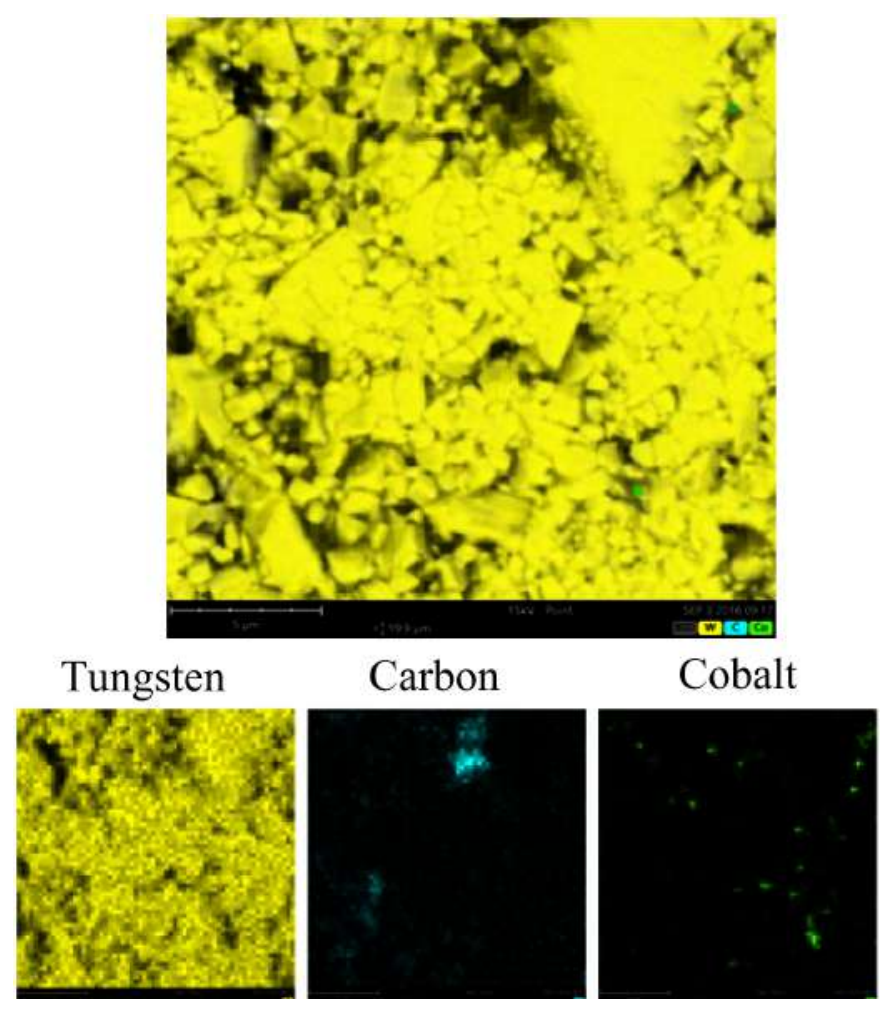

Figure 4 Mapping for the distribution of elements in WC-Co material

Table 2 Quantification of the roasted waste by EDS

\begin{tabular}{cccc}
\hline $\begin{array}{c}\text { Element } \\
\text { name }\end{array}$ & $\begin{array}{c}\text { Element } \\
\text { symbol }\end{array}$ & $\begin{array}{c}\text { Element } \\
\text { number }\end{array}$ & $\begin{array}{c}\text { Element } \\
\text { weight }\end{array}$ \\
\hline Tungsten & $\mathrm{W}$ & 74 & 81.12 \\
Cobalt & Co & 27 & 1.68 \\
Carbon & $\mathrm{C}$ & 6 & 10.67 \\
Oxigen & 0 & 8 & 6.53 \\
\hline
\end{tabular}

homogenous way throughout the sample. The phases of the formed oxides can be determined by XRD analysis, which will be done next.

\subsection{Thermodynamic study of the waste oxidation process}

Using HSC Chemistry 6.0 and its module of reaction equations, the feasibility of the reactions for the oxidation process was evaluated. In the module, the species that make up the base material were entered: tungsten carbide (WC) and cobalt (Co), in addition to a certain amount of oxygen in the air. The possible oxidation reactions are shown in Table 3, and the enthalpy of reaction and the free energy of $\mathrm{Gibbs}$ at $900^{\circ} \mathrm{C}$ are taken as reference, as mentioned in the literature [1].

Based on the data obtained in the module of reaction equations, the Gibbs' free energy indicates that the previous reactions at $900{ }^{\circ} \mathrm{C}$ is spontaneous and the enthalpy shows that it is an exothermic reaction, hence the reactions listed above are thermodynamicaly feasible.

According to the results of the XRD analysis (Figure $6)$, it is determined that the first and last reactions of Table 3 occur, that is, two types of oxides are formed: tungsten trioxide $\left(\mathrm{WO}_{3}\right)$ and a complex cobalt-tungsten oxide $\left(\mathrm{CoWO}_{4}\right)$. Because most of the starting material is tungsten (> $80 \% \mathrm{~W}$ ), most of the oxide formed is tungsten trioxide (> $90 \% \mathrm{WO}_{3}$ ).

\subsection{Thermodynamic and kinetic study of the reduction process}

For the thermodynamic information, the HSC Chemistry 6.0 software was used. The product resulting from the oxidation of the waste was taken as starting materials: $90.7 \% \mathrm{WO}_{3}$ and $9.3 \% \mathrm{CoWO}_{4}$. In the module, the species and amounts are entered together with the reducing agent that, in this specific case, is hydrogen.

For the kinetic curves, the reduction process was carried out in chemical absorption equipment, (RPT), to evaluate the hydrogen consumption peaks by means of temperature increases, which indicate changes in the phases of the oxides introduced. 

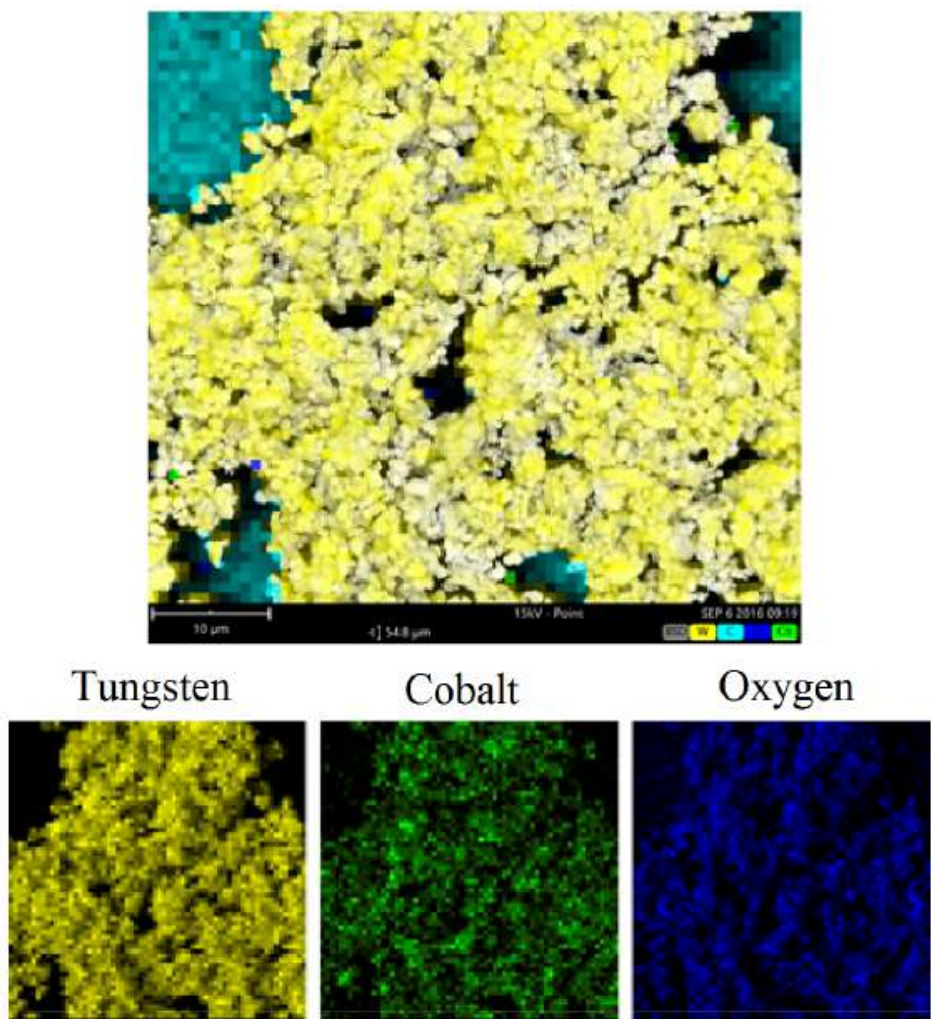

Figure 5 Mapping for the distribution of elements in the oxidized material

Table 3 Oxidation reactions proposed

\begin{tabular}{ccc}
\hline Reaction & $\begin{array}{c}\Delta \mathrm{H} \text { at } 900^{\circ} \mathrm{C} \text { of } \\
\text { reaction }[\mathrm{KJ} / \mathrm{mol}]\end{array}$ & $\begin{array}{c}\Delta \mathrm{G} \text { at } 900^{\circ} \mathrm{C} \\
{[\mathrm{KJ} / \mathrm{mol}]}\end{array}$ \\
\hline $\mathrm{WC}+5 / 2 \mathrm{O} \rightarrow \mathrm{WO} 3+\mathrm{CO} 2$ & -1182.337 & -904.373 \\
$2 \mathrm{Co}+\mathrm{O} 2 \rightarrow$ 2CoO & -465.948 & -303.036 \\
$\mathrm{WC}+\mathrm{Co}+302 \rightarrow \mathrm{CoO} \cdot \mathrm{WO} 3+\mathrm{CO} 2$ & -1469.123 & -1117.379 \\
$\mathrm{WC}+\mathrm{Co}+302 \rightarrow \mathrm{CoW} 4+\mathrm{CO} 2$ & -1604.128 & -1014.136 \\
\hline
\end{tabular}

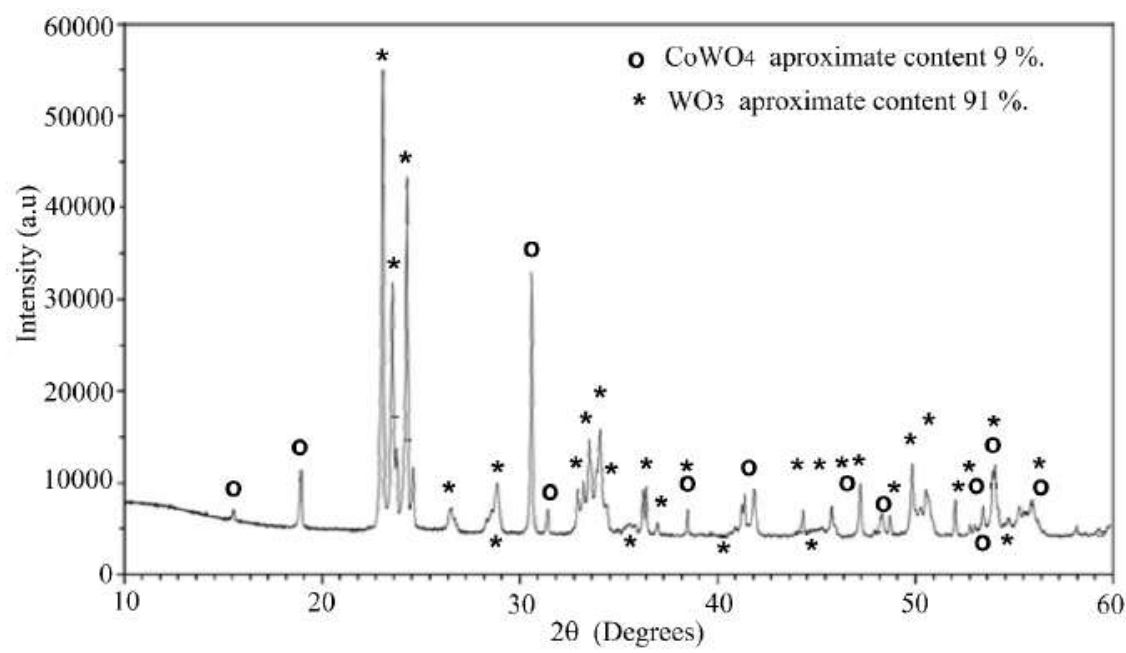

Figure 6 Diffraction pattern of the product of the roasted waste 
By combining the graphics obtained from both the thermodynamic and the kinetic study (see Figure 7), the temperatures at which the transformations occur and to what species they can be related are clearly observed.

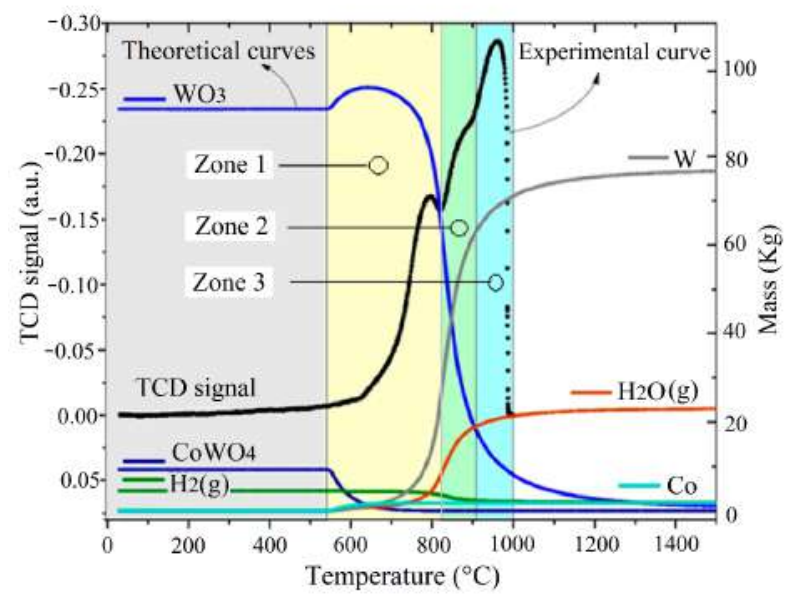

Figure 7 Combination of thermodynamic and kinetic study of $\mathrm{WO}_{3}$ and $\mathrm{CoWO}_{4}$ oxide reduction

In Figure 7, it can be seen that the reduction of the $\mathrm{CoWO}_{4}$ and $\mathrm{WO}_{3}$ oxides is thermodynamically feasible using hydrogen as a reducing agent. The thermodynamic analysis predicts that the reduction of tungsten trioxide starts at $550^{\circ} \mathrm{C}$ and ends at $1500^{\circ} \mathrm{C}$. However, the kinetic analysis (with a $10^{\circ} \mathrm{C} / \mathrm{min}$ ramp) indicates the appearance of the following zones: in the first zone lbetween 550 and $820^{\circ} \mathrm{C}$ ) the decomposition of the oxides present begins; the second zone (between 820 and $910^{\circ} \mathrm{C}$ ) indicates a $50 \%$ progress both in the reduction of trioxide and in the formation of metallic tungsten, and in the third zone (between 910 and $1000^{\circ} \mathrm{C}$ ) $80 \%$ progress of the reaction is observed, up to this point the process lasts $100 \mathrm{~min}$. The remaining $20 \%$ of the process is carried out between 1000 and $1500^{\circ} \mathrm{C}$. It is observed that during the entire reduction process since the transformation begins, water formation occurs, which indicates a thermodynamically feasible reduction. The possible reduction reactions that take place are shown in Table 4.

\subsection{Calculation of apparent activation energy}

For the determination of the kinetic parameters of the reduction process, it is necessary to carry out a minimum of three tests with different heating speeds. In this case, three reduction tests were performed at programmed temperature (RPT) with heating ramps of 1,5 and 10 ${ }^{\circ} \mathrm{C} / \mathrm{min}$. The resulting graphs are displayed in Figure 8.

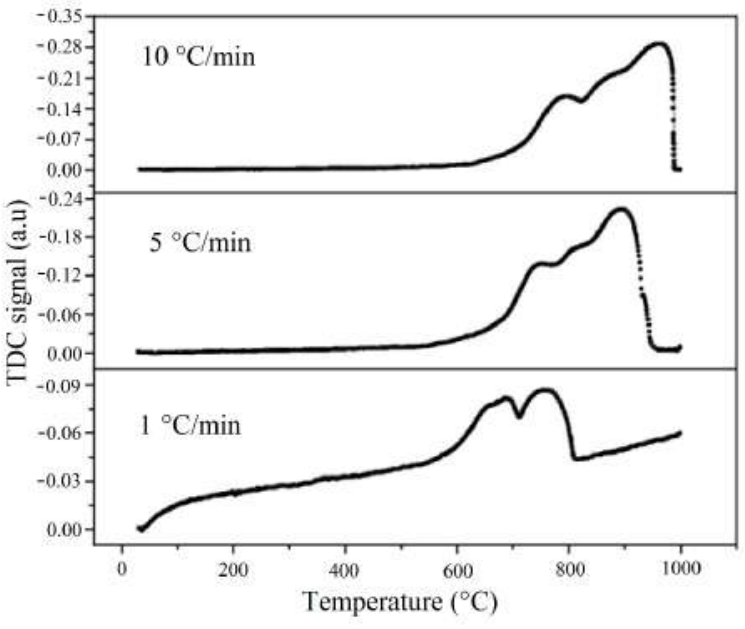

Figure 8 PTR diagrams with ramps of 1,5 and $10{ }^{\circ} \mathrm{C} / \mathrm{min}$

From Figure 8 the temperatures at which hydrogen consumption is higher and the value of the heating ramp are determined, then $\operatorname{Ln}\left(\frac{\beta}{T_{\max }^{2}}\right)$ is calculated [12]. These values correspond to the axis $Y$ and $\left(\frac{1}{T_{\max }}\right)$ equivalent to the values of $X$, where $B$ is the heating rate and $T_{\max }$ is the temperature at which the peak of highest hydrogen consumption occurs [12]. During the reduction process, it is observed that for a lower heating rate, the temperature at which the sample begins to consume hydrogen is lower, which may be due to the fact that the slower the heating, the greater the opportunity for the oxides to react with the reducing gases of the system. Finally, based on Figure 9, it is determined that the activation energy is $102.604 \mathrm{~kJ} / \mathrm{mol}$. The calculated activation energy is considerably high, implying that the reduction is predominantly controlled by chemical reaction kinetics between the reactants, not by mass transfer of the reducing agent in the gas phase to the particle surface. Different activation energies have been reported by several researchers for the reduction of $\mathrm{WO}_{3}$ by $\mathrm{H}_{2}$, i.e., from $83 \mathrm{~kJ} / \mathrm{mol}$ to $134 \mathrm{~kJ} / \mathrm{mol}$ [14]; it can be observed that the values of tungsten activation obtained using Coats and Redfern method show reasonably good agreement.

\subsection{Characterization of reduction products}

After the reduction process with hydrogen, the resulting material was characterized by XRD, showing that the predominant phases are metallic $\mathrm{W}$ with a concentration of $98.6 \%$ and metallic Co with a concentration of $1.4 \%$ approximately. The corresponding diffraction pattern is shown in Figure 10. 
Table 4 Theoretical reduction reactions for $\mathrm{WO}_{3}$ and $\mathrm{CoWO}_{4}$ oxides

\begin{tabular}{ccc}
\hline Reaction & $\Delta \mathrm{H}$ of reaction $[\mathrm{KJ} / \mathrm{mol}]$ & $\Delta \mathrm{G}[\mathrm{KJ} / \mathrm{mol}]$ \\
\hline CoWO4 $+4 \mathrm{H} 2 \rightarrow \mathrm{Co}+\mathrm{W}+4 \mathrm{H} 20$ & $\Delta \mathrm{H} 610^{\circ} \mathrm{C}=220.34$ & $\Delta \mathrm{G} 610^{\circ} \mathrm{C}=-1.476$ \\
CoWO4 $+\mathrm{H} 2 \rightarrow \mathrm{Co}+\mathrm{WO} 3+\mathrm{H} 20$ & $\Delta \mathrm{H} 500^{\circ} \mathrm{C}=112.637$ & $\Delta \mathrm{G} 500^{\circ} \mathrm{C}=-1.349$ \\
WO3 $3 \mathrm{H} 2 \rightarrow \mathrm{W}+3 \mathrm{H} 20$ & $\Delta \mathrm{H} 830^{\circ} \mathrm{C}=81.763$ & $\Delta \mathrm{G} 830^{\circ} \mathrm{C}=-0.417$ \\
\hline
\end{tabular}

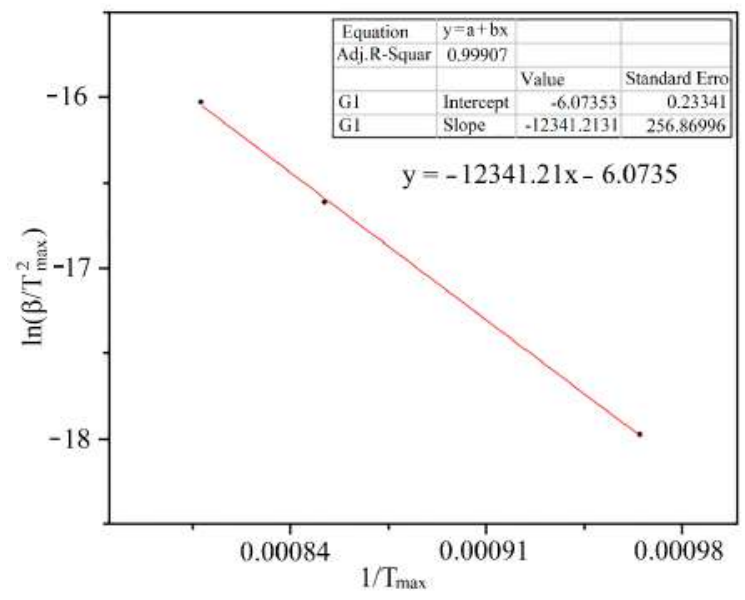

Figure 9 Kissinger graph for calculating the activation energy

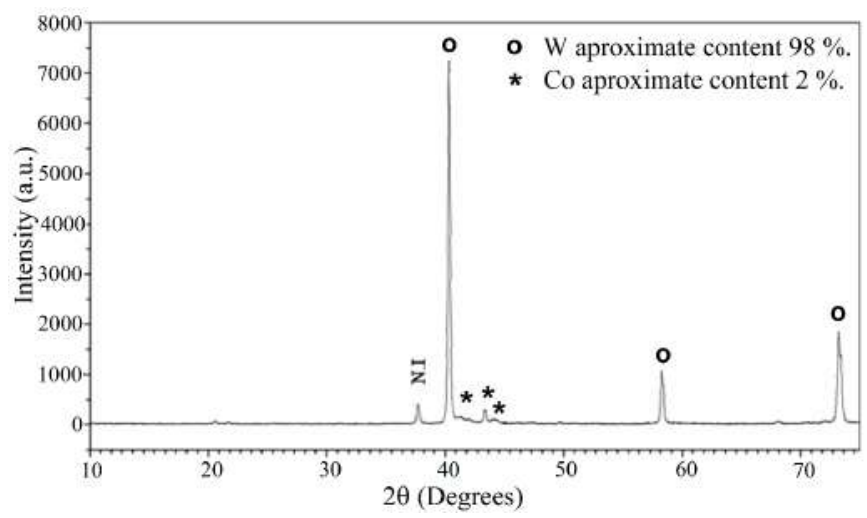

Figure 10 Diffraction pattern of material reduced with hydrogen

Based on the thermodynamic study and laboratory tests, the reduction of CoWO4 and WO3 oxides gives two metals: tungsten and cobalt, as can be seen in Equations (1) and (2).

$$
\begin{gathered}
\mathrm{CoWO}_{4}(s)+4 \mathrm{H}_{2}(g) \mathrm{Co}(s)+\mathrm{W}(s)+4 \mathrm{H}_{2} \mathrm{O}(\mathrm{g}) \\
\mathrm{WO}_{3}(s)+4 \mathrm{H}_{2}(g) W(s)+3 \mathrm{H}_{2} \mathrm{O}(\mathrm{g})
\end{gathered}
$$

The above equations were checked with the XRD analysis performed to the reduced material and therefore, this indicates that the process is effective for obtaining $W$ and Co in metallic form from metalworking industry waste.

\section{Conclusions}

The oxidation and pyrometallurgical reduction behavior of tungsten from tungsten carbide-cobalt tool waste was investigated, and the major conclusions of the present study are as follows.

- The thermodynamic study of the oxidation process of tungsten carbide-cobalt waste predicts the formation of four phases of oxides; however, the results of the XRD analysis showed that only two phases were found in the oxidation product: $\mathrm{WO}_{3}$ and $\mathrm{CoWO}_{4}$.

- The thermodynamic analysis predicts tungsten and cobalt formation from the reduction of the product of oxidation with hydrogen at the temperature range 550 $-1500^{\circ} \mathrm{C}$.

- The kinetic analysis of the reduction process shows a $50 \%$ progress between 820 and $910^{\circ} \mathrm{C}$ both in the reduction of trioxide and in the formation of metallic tungsten; and between 910 and $1000^{\circ} \mathrm{C}$ an $80 \%$ progress in the reduction process of $\mathrm{W}$.

- It was determined that a low heating rate in the reduction process gives a low temperature at which the sample starts to consume hydrogen and therefore, to be reduced.

- The activation energy calculated for the reduction of $\mathrm{WO}_{3}$ is considerably high $(102 \mathrm{~kJ} / \mathrm{mol})$, implying that the reduction process is predominantly controlled by the chemical reaction kinetics between the reactants.

- The tungsten activation values obtained using Coats and Redfern method show reasonably good agreement with the literature.

\section{References}

[1] S. Kim, B. Seo, and S. Son, "Dissolution behavior of cobalt from WC-Co hard metal scraps by oxidation and wet milling process," Hydrometallurgy, vol. 143, pp. 28-33, Mar. 2014.

[2] U. D. of the Interior and U. G. Survey, Mineral Commodity Summaries 2018. Reston, VA: U.S. Geological Survey, 2018.

[3] V. A. y F. Romero y M. Salvador y D. Busquets, "Reactividad matriz-refuerzo en compuestos de matriz de titanio pulvimetalúrgico," Revista de Metalurgia, vol. 43, no. 6, 2007.

[4] W. F. Smith and J. Hashemi, Foundations of Materials Science and Engineering, 4th ed. México: McGraw-Hill, 2004.

[5] S. Kalpakjian and S. Schmid, Manufacturing Engineering and Technology, 6th ed. New York: Prentice Hall, 2009. 
[6] B. Liu and et al, "Recovery of tungsten carbides to prepare the ultrafine WC-Co composite powder by two-step reduction process," Powder Technology, vol. 306, pp. 113-119, Jan. 2017.

[7] U. D. of the Interior and U. G. Survey, Tungsten Recycling in the United States in 2000. Reston, Virginia: U.S. Geological Survey, 2011.

[8] E. Altuncu, F. Ustel, A. Türk, S. Ozturk, and G. Erdoğan, "Cutting-tool recycling process with the zinc-melt method for obtaining thermal-spray feedstock powder (wc-co)," vol. 47, pp. 115-118, Jan. 2013.

[9] R. Paul, W. Te Riele, and M. Nicol, "A novel process for recycling tungsten carbide scrap," vol. 15, pp. 41-56, Aug. 1985.

[10] M. Latha and S. Venkatachalam, "Electrolytic recovery of tungsten and cobalt from tungsten carbide scrap," Hydrometallurgy, vol. 22, no. 3, pp. 353-361, Aug. 1989.

[11] A. Vesel, M. Mozetic, and M. Balat, "Phase transformation in tungsten carbide-cobalt composite during high temperature treatment in microwave hydrogen plasma," Ceramics International, vol. 38, no. 8, pp. 6107-6113, Dec. 2012.

[12] J. Gallego, G. Sierra-Gallego, J. Tapia, F. Mondragón, and C. Batiot-Dupeyrat, "Activation of CO2 on Ni/La2O3: non-isothermal kinetic study on the basis of thermogravimetric studies," Reaction Kinetics, Mechanisms and Catalysis, vol. 119, no. 1, pp. 179-193, Oct. 2016.

[13] A. S. Kurlov and A. I. Gusev, "Tungsten carbides and W-C phase diagram," Inorganic Materials, vol. 42, no. 2, pp. 121-127, Feb. 2006.

[14] S. Cetinkaya and S. Eroglu, "Reduction of tungsten trioxide with ethanol," Int. J. Refract. Met. Hard Mater., vol. 64, pp. 184-189, Apr. 2017.

[15] E. Bedolla, C. León, and E. Aguilar, "Aplicación de técnicas cinéticas no isotérmicas en la reducción de tres minerales de hierro de grado comercial," Revista de Metalurgia, vol. 33, no. 4, pp. 239-249, 1997. 